\title{
A Career-History Analysis of Gender Differences in Publication Productivity among South African Academics
}

\author{
Heidi Prozesky
}

Decades of research on gender differences in academic publication productivity has as yet provided very little, if any, empirical support for the common sense understanding that a certain measure of incompatibility exists between being a mother and a productive academic researcher. In an attempt to start unravelling the complexity of this productivity puzzle in the South African context, data collected from Curriculum Vitae (CVs) are integrated with qualitative interview data. This methodological approach provides a detailed view of publication patterns, couched within the context of an in-depth perspective on the career histories of sixteen of the country's top-performing academics. The study identifies important ways in which women and men approach their early academic and family lives differently, with divergent consequences for their career publication productivity.

Keywords: publication productivity, gender, early academic careers

The communication of research findings and results is one of the most fundamental social processes of science (Fox, 1983). In correspondencewithinternationaltrends, one form of scientific communication, the peer-reviewed article, is being accorded an increasingly central role in the academic reward system in South Africa (Department of Education, 2001). At the same time, a gender gap in publication productivity has been shown to exist in South Africa: although women have been strengthening their representation at South African Higher Education Institutions (HEIs), a recent analysis of a bibliometric database of peer-reviewed journal articles and their South African authors (termed SA Knowledgebase) demonstrates that, between 1990 and 2001, men at HEIs published in aggregate almost twice as much as their female counterparts did (Prozesky, 2006a). The analysis also indicates that the most productive male authors far exceed the most productive women in terms of quantity of peer-reviewed article output.

These findings are similar to those produced by a large body of research conducted in a various countries, which has established that women consistently produce less in terms of published scientific output than men do (see Prozesky, 2006b for a detailed review). The past few decades' literature on the subject reveals that three possible sets of explanations for the gender 
gap in publication productivity may be distinguished: (1) the "difference model", according to which publication productivity differences between women and men originate from deep-rooted differences in the behaviour, outlook and goals of the sexes (Sonnert, 1999), which are presumed to be the result of differential gender-role socialisation; (2) workplace-related explanations, which form the "deficit model": the hypothesis that academic women publish less than men do, because of structural deficits of the organisations in which they work (Sonnert, 1999: 42) that may limit women's access to the means of scientific production (material research resources), and/or exclude them from maledominated networks; and (3) external, non-workplace factors, in particular women's heavier load in terms of familyrelated responsibilities.

The greater part of the empirical evidence with regard to the latter seem to indicate that, at least on their own, family responsibilities do not cause gender differences in publication productivity, and that married women publish more than single women and/or that mothers publish more than childless women (Nakhaie, 2002; Sax et al., 2002; Harper et al., 2001; Barnett et al., 1998; Davis and Astin, 1990; Kyvik, 1990; Long, 1990; Cole and Zuckerman, 1987; Astin and Davis, 1985; Fox and Faver, 1985; LuukkonenGronow and Stolte-Heiskanen, 1983; Wanner et al., 1981; Helmreich et al., 1980; Cole, 1979; Astin, 1978; Reskin, 1978 a, b; 1977; Hamovitch and Morgenstern, 1977; Astin and Bayer, 1975; Williams et al., 1974; Cole and Cole, 1973; Simon et al., 1967). Thus, the intuitive belief that marriage and motherhood cannot be meshed with a demanding scientific career has been termed an "empirically untenable stereotype” (Toren, 1991: 667), or a "motherhood myth", and it is argued that the myth itself, rather than marriage and motherhood, may be the source of incompatibility in women's careers (Etzkowitz et al., 2000).

It seems that this perception of incompatibility between a family and an academic career varies from country to country, depending on how strongly the emphasis on the essential nature of the mother's care for children is in a particular socio-cultural context (see Kyvik and Teigen, 1996; Kyvik, 1991 ; 1990). Also, indications are that differences among women scientists from various countries in terms of their role and status are stronger than they are among the institutional settings within a given country (Chakravarthy et al., 1988). However, most research that aims to link gender differences in publication productivity to marriage and/or motherhood derives from the mainstream of the world science centres, in particular the United States (Fox, 1995; LuukkonenGronow and Stolte-Heiskanen, 1983). Considering the variable effects that different socio-cultural settings may have, the conclusions drawn from mainstream studies should be tested in other sociocultural contexts.

South Africa, for instance, may differ from other countries in terms of the extent to which unspoken pressures are exerted on women-and for that matter, men-to conform to certain 'feminine' or 'masculine' roles. Certainly, the strong patriarchal and apartheid ideologies that characterised our country in the past meant that most women who began their academic careers two to three decades ago, did so under circumstances characterised by strong gender-role stereotypes-including traditional values that demand of women to accord a very high priority to their homes, families and husbands ${ }^{1}$-and the apartheid system that reinforced male dominance at HEIs 
(National Research Foundation, 2001). However, in the South African context, only a very small number of empirical studies (Maürtin-Cairncross, 2003; Centre for Interdisciplinary Studies ${ }^{2}, \quad 2001$; Seedat, 1992, cited in Shefer et al., 1997; and White, 1989) have thus far focused on any gender issues related to academic publication productivity. As MaürtinCairncross (2003: i) rightly observes: there is a "dearth in research regarding women's publishing records and women's relationship with publishing" in South Africa.

The research reported in this paper is aimed at addressing this gap in the literature by developing a better understanding of how gender is related to the issues of career age, time to $\mathrm{PhD}$, family responsibilities and early (pre$\mathrm{PhD}$ ) publication productivity in South Africa. It has been noted elsewhere that women take longer than their male counterparts to attain a $\mathrm{PhD}$ (Asmar, 1999; Probert et al., 1998, cited in Chesterman, 2002; Xie and Shauman, 1998; Toren, 1991), which might reflect a tendency for women to delay the earning of this degree until having children, as Toren (1991) found to be the case in Israel. Considering the fact that time between a bachelor's degree and the PhD has been found to have a negative effect on productivity (Xie and Shauman, 1998), it is important to focus on the way in which time to $\mathrm{PhD}$ may contribute to women's lower rates of publication productivity relative to men's.

The present study is aimed at doing so, by presenting data on the ways in which women and men approach their early academic and family lives differently. Most studies on gender issues in academia, and all of those conducted thus far in South Africa, have investigated women only. Although these studies provide, in part, an understanding of factors that affect the productivity of women academics (cf. Maürtin-Cairncross, 2003; National Research Foundation, 2001; Centre for Science Development, 1999), such an approach does not provide a clear understanding of whether the experiences women faculty report are to a large extent gender specific. As Karp (1985) explains, one needs to draw on the experiences of men in order to place the women's lives in proper perspective.

\section{Research methodology}

For the purpose of this study, sixteen depth interviews with eight men and eight women were conducted telephonically ${ }^{3}$, tape-recorded and transcribed verbatim. The interviews consisted of open-ended questionsfocusedonbroad themesrelated to publication productivity, as informed by a review of previous empirical and theoretical work on gender differences in publication productivity, as well as by longitudinal career data collected from the participants' CVs (which were requested prior to conducting the interviews).

A qualitative approach was chosen in response to the need that has been highlighted in the literature for a more detailed, nuanced and contextualised understanding that goes beyond simply correlating the number of papers published with marital and parental status (Maürtin-Cairncross, 2003; De la Rey, 1998; Cole and Zuckerman, 1984). As is the case in most studies where qualitative methods are used (Babbie and Mouton, 2001:288), the respondents were selected purposively according to a number of sampling criteria identified as pertinent to the study. In contrast to random sampling that is used in quantitative studies, this qualitative study therefore follows an idiographic, rather than nomothetic research strategy, in order to maximise 
the range and depth of insights generated (Babbie and Mouton, 2001), rather than generalising the findings to a larger population. Although one may argue that the research lacks external validity, qualitative data is generally considered to have high internal validity and reliability, particularly when, as in this case, it is combined with $\mathrm{CV}$ data, thereby allowing for a triangulation of methods (Babbie and Mouton, 2001: 275).

A particular focus of the research is to compare women and men on what they consider to be factors that have influenced or affected one aspect of their occupational achievement, i.e., their publication productivity. This strategy requires a chronological reconstruction of a relatively small number of 'publication success stories' over time to allow one to consider, from a life course perspective, the dynamic relation between family life and publication productivity. Potential respondents were therefore narrowed down to only those academics that may be defined as most 'successful' or prominent in terms of scientific publications ${ }^{4}$.

The advantages associated with such an approach are as follows: First, all of these academics have already reached the highest academic qualification (a PhD) and position of seniority (full professor). Thus, the whole span of the academic career, including barriers to publishing, as well as possible advantages of being in a senior position, may be traced for each respondent, from their pre- $\mathrm{PhD}$ publications to their highly productive situation in the present. Such a long-term view is preferable, as gender differences in publication productivity do not remain stable over a career (Long, 1992).

Secondly, the purposive sampling allows for an approximation of a matched pair design that controls not only for variables such as academic qualification and rank mentioned above, but also for type of institution and discipline (the respondents are all affiliated with Historically Advantaged Universities ${ }^{5}$, and the majority work in the natural or health sciences - scientific domains that arguably expect and reward the publication of relatively short, peerreviewed journal articles more than the social sciences and humanities do). This matching allows one to 'tease out' more easily the direct effect that gender alone may have on publication productivity. And because it is highly probable that the major producers of publications (who are all over 40) entered academia at approximately the same time, the purposive sample also controls for varying historical contexts that influence both the work environment (e.g., the probability of promotion) and values relating to women's role in society.

A database of South African authors of peer-reviewed journal articles, SA Knowledgebase, was utilised to select the most prolific South African producers within each gender group. This quantitative criterion was complemented by a more qualitative requirement for selection, by including only those scientists who are rated by the South African National Research Foundation, on the basis of the quality of their scientific contributions, as at least 'internationally acclaimed' researchers ${ }^{6}$. Further, only respondents who were affiliated to an academic institution at the time of the interview were considered for selection. This criterion controls for employment sector variability (Stephan and Levin, 1992; Long and McGinnis, 1981) and makes practical sense in the South African context, where academics are responsible for more than 80 percent of the country's visible research outputs (Pouris, 2003; Department of Arts, Culture, Science and Technology ${ }^{7}$, 1998). 
On the other hand, selecting a homogenous group of 'superwomen' also implies selecting 'survivors' (Levinson et al., 1989: 1516) in the extreme, who have very successfully managed their family and academic roles simultaneously. It therefore has to be acknowledged that the knowledge about the effect of family responsibilities and a scientific career that is generated by this study excludes the large majority of women who have not succeeded to the same extent as the small sample studied, and as such may understate the effect of family responsibilities on women's scientific careers. However, previous research conducted by the author (Prozesky, 2006a) found that even the most productive women-women that are chronologically and professionally mature and at the top of the academic qualification and rank hierarchy-publish less than the most productive men. The research presented in this paper attempts - for the first time in South Africa - to provide some answers to why this is the case, by focussing specifically on these most productive women and comparing them with their male counterparts in terms of their early career and family experiences.

\section{Data analysis and interpretation}

In terms of chronological age, the men and women respondents do not differ much: on average, the women are slightly younger (54) than their male counterparts (56). More important in an analysis of publication productivity, however, is the notion of career age, measured as the number of years since the respondent has obtained his/her $\mathrm{PhD}$ (see Allison and Steward, 1974). It is also in relation to this feature of the respondents-one that reflects seniority and/or years of professional experience - that one finds a more pronounced difference between the men and women. While the men in the study had amassed an average of 26 years of professional experience by the time of the interviews, the women averaged a career age of only 20 years.

The combined chronological and career age data obtained from the CVs show that this gender difference results mainly from the women obtaining their PhDs at a later average chronological age (34) than the men do (30), and while half of the women were older than 33 when they obtained their PhDs, by the age of 33 all of the men had achieved this important milestone in their academic publication careers. As frequent academic publication is usually only initiated after the completion of a PhD ("When I had finalised my dissertation, I could start, as it were", a female respondent explains), the women's considerably younger career age would most probably count against them in terms of career publication productivity.

An important question to answer in this regard is: Did the women initiate their doctoral studies at a later stage in their lives, or did they merely take longer to complete it? The number of years between graduation dates for master's and doctoral level qualifications, which may be gleaned from most respondents' CVs, provides one with an indication of whether the women already lagged behind the men in their academic training at a pre- $\mathrm{PhD}$ stage. The data show that, on average, the women are characterised by a longer time lag of seven years between attaining their master's and doctoral degrees, compared to the men's four years.

However, there is a smaller gender gap of only three years in the average age at which respondents obtained their master's degrees. Moreover, the men and women do not differ at all in terms 
of the age at which they were awarded their first degrees. This may indicate that processes of accumulation of advantage for men and disadvantage for women, as proposed by Cole (1979), already operate in the early academic career histories of even highly productive academics.

It is important to determine what initially produces the time lag between the master's and doctoral qualifications, which arguably sets the process of disadvantage accumulation into motion. The argument that women are less able than men to complete their doctoral research within a shorter time period, owing to the fact that they are innately less able as scientists than men are, is not supported by evidence from previous studies (Cole, 1979; Committee on the Education and Employment of Women in Science and Engineering, 1979; Harmon, 1965 and NAS, 1968, both cited in Graham, 1970). In this sample, the conversion of a master's thesis to a $\mathrm{PhD}-$ an indicator of exceptional scientific ability-was also found to be equally likely to occur among the sexes. Actually, it may be argued that, because the women in this study have succeeded in forging highly productive careers in spite of strong patriarchal and apartheid ideologies referred to in the introduction, they may even be a more highly select group than the men in terms of abilities needed to become a productive academic scientist.

The fact that the gender gap in time to degree increases as the women reach their childbearing years leads one to suspect a tendency among the women to delay the earning of a $\mathrm{PhD}$ until having one or two children. In order to further investigate this issue, selected features of the career and life histories of those women respondents who experienced the largest gap between their master's and doctoral degrees, are investigated.

\section{"I sort of threw that up": postponing the PhD}

As expected, for most of the women for whom the time between attaining their master's and doctoral qualifications is greater than the average (six years) for the sample as a whole, bearing and raising of children did lead to a postponement of their publication careers. In Linda's case, at the time her two children were born (approximately two years apart) she was already working on her doctoral dissertation, which she finished when her children were not yet of schoolgoing age. Combining the writing of a dissertation and children's "baby days" is described by her as "very difficult at times", and "rather exhausting". Based on her own experience, Linda's advice to the next generation of academic women is to change the chronological order of the life-changing event of childbearing, and the career-changing event of a $\mathrm{PhD}$ :

“...the moment you are finished with your dissertation, and you would like to have children, do it then. You will probably find that it is easier for you to handle, even though your career takes longer to take off".

Other women respondents who combined their postgraduate studies with childbearing, such as Cecilia, also warn against the difficulties associated with this strategy:

“...you'll always feel guilty - whatever you're doing: if you're playing with your children, it's the worst thing when you're writing a thesis".

Some of the women not only started their publication careers at a later stage than the men did, but entered academia only after they had pursued other careers. 
Elmarie, for example, was a school teacher who only achieved her master's degree in her mid-thirties, "... and then a very long road with a PhD”, because - like most of the other women - she was also studying part-time and had two small children.

What is interesting to note is the fact that Elmarie's career trajectory was not only shaped by motherhood, as her academic career was initiated by her husband's career change from private practice to academia, when she became what Harper et al. (2001: 242) refer to as the "trailing spouse" (most often the wife), who began teaching part-time at the same university as her husband.

The effect of women shaping their professional lives in relation to the careers of their partners is probably most clearly visible in Sarah's career history. She evinces the most substantial gap of thirteen years between obtaining a master's and a doctoral qualification, but, counter-intuitively, has no childrenone of the reasons why she "managed to publish quite well", according to her. However, it is also clear from Sarah's narrative that meeting and marrying her husband directly contributed to the postponement of her $\mathrm{PhD}$ :

“...the National Research Foundation gave me a bursary to start doctoral research at [a research station], and there I met someone I decided to marry. And so, I sort of threw that up and I went and worked as a sign-writer, a secretary, and did other things...I... wasn't an academic at all [for three years in the eighties]: I was a secretary and private consultant...Well, I had been considering [a PhD] in [the early eighties], but then when I met my husband, he decided to...go and build boats... and so I left the nature reserve to follow him down there, and then helped him in the boatyard with accounts, stuff like that. So, it wasn't really an ideal environment...I couldn't continue the PhD I wanted to do in [one] province, because I was then living in la town in another province]".

Even if the $\mathrm{PhD}$ is not postponed, marriage-related factors may inhibit a post-PhDincrease in woman's publication productivity, as illustrated by the parallel careers of a married couple ${ }^{8}$ who coauthor extensively. In order to ensure a higher level of synergy in their work, the wife (Beatrice) - and not her husbandchanged her research focus, because she had just finished her $\mathrm{PhD}$ and was not yet as established a scientist as her husband (she is both chronologically and professionally younger than him). Such a change tends to have a negative effect on publication productivity, at least for a few years, resulting in what Beatrice refers to as "a bit of a lag".

Previous research has shown that the academic careers of men follow a much more orderly, or at least linear, progression (De la Rey, 1999; Lie, 1990; Karp, 1985). It is therefore not surprising that Charles is the only male respondent who evinces a time period between his master's and doctoral qualifications, which is similar in scope to what most women exhibit (eight years). However, the postponement of his $\mathrm{PhD}$ is not family-related, as his first child was born twelve years after completing his $\mathrm{PhD}$. Rather, Charles attributes the fact that his "PhD took a long time" to the fact that he combined his postgraduate studies with full-time employment at a South African university and consultancy research work. Although one would expect this to have stifled Charles's publication output at least initially, he exhibits the second highest pre-PhD article count of all the respondents, which he (paradoxically) attributes to his early academic appointment: 
"I was working in the department as a junior lecturer when I was doing my master's, and the department's policy was always to encourage people to publish. They would encourage you to go to conferences. So it is a very good sort of start in life...It was a generally supportiveenvironment, anencouraging environment to 'do the academic thing' - just to go to conferences, present papers and publish".

According to the accumulative advantage hypothesis (Cole and Cole, 1973), such a prolific early start generally has a positive effect on later publication productivity. It is therefore important to note that, according to the CV data, the women on average (co-)authored a much smaller number of pre-PhD articles (5) that the men (12) did.

\section{"You had to find your own way": early academic socialisation}

As Charles's experience illustrates, the academic environment into which one is socialised is a crucial facilitator of publication productivity during graduate training. One gender difference with regard to early academic socialisation that emerged from the qualitative interviews is that the men report exposure to a publication-enhancing environment that socialised them to value research in their careers to a greater extent than the women do. According to Leon, his early academic environment encouraged early PhD attainment- "Right from the start, if you step into the faculty, you are encouraged, and actually more or less called upon to start working on your doctoral degree"- and conveyed a strong message that publication is not "a luxury that is added afterwards".

The women tend to report the opposite, and in particular a lack of a research and publication culture at South African universities during their pre-PhD years of their academic employment. Linda's description of the "atmosphere" that prevailed during the eighties stands in stark contrast to Charles and Leon's experiences. She describes "an academic establishment that was not very focused on the development of young lecturers - or not as focused on it as much as now", characterised, in her field, by:

“...professors who did not actually attend congresses; or who never encouraged you to do so, or who did not set an example for you in that regard... As a young person, one was not told: 'It will be good to attend this congress, or that congress'”.

Elmarie provides a very similar account of her experiences at the university where she was employed during the seventies:

“...there was no publication culture at all...It was not expected of us...it is quite simple: it was not part of the way of thinking".

One male respondent, Bob, corroborates these women's observation on the lack of a research culture that characterised South African universities a few decades ago:

"I think that certainly around the 1970s there wasn't really much research being done in South Africa in universities - at least not in [the] departments that I was in. So, there was really no research culture - very little research culture in the department [where I worked] before the 70s in South Africa. So, I hadn't really been exposed to a research culture in the 60s". 
However, while Linda expresses regret at not being exposed to the workings of a true academic research career, Bob does not mention any negative effects of the prevailing institutional culture on his own publication productivity, primarily because he was more mobile than Linda and Elmarie were during their graduate training. While both these women combined their graduate studies with the raising of young children, which limited their opportunities to further an academic research career overseas, Bob is childless, and was therefore able to study for his $\mathrm{PhD}$ in the United States, where he was exposed to a more dynamic research culture:

"I was in...one of the leading departments [in my field] in the world, and there was a research culture, which appealed to me enormously, and I kind of feel that I brought it back with me... starting it in [my original field] in South Africa, and have contributed to bringing it into [my new field] here".

Although the women tend to emphasise the negative effect of the prevailing institutional culture on their early publication productivity, a number of them emphasise the important positive influence mentors have had on their careers. Elmarie recalls that a male mentor, an "outsider" whom she met at a conference, explained to her the importance of publishing her research results, particularly in the international literature-otherwise they "mean nothing". She followed his advice, with the result that her work became wellknown internationally, before it received any local recognition.

In Delia's case, the fact that her supervisor had been working "a long time" in the field of study she chose for her $\mathrm{PhD}$, meant that he "knew where the forefronts were, so it was very quick and easy to get to that". Cecilia mentions one mentor who saw her potential and encouraged her to present at a conference a paper that she later published, as well as some other "nice mentors" who supported her and recognised her work. Sarah also reports that she had "outstandingly good mentors" and supervisors who "helped [her] a lot".

Linda is an exception, as she explicitly refers to her experience of a "lack of academic guidance - or mentoring, encouragement - that was typical of the eighties". Consequently, she does not attribute her career success to the influence of any mentors: "You had to just do your own thing; you had to find your own way", she explains. Linda's narrative illustrates the argument posed by Maürtin-Cairncross (2003) and Sonnert (1999) that, because women academics are less likely to be mentored, they may not know exactly what the (androcentric) expectations of the academic role are. The effect of this lack of orientation on particularly the first few years of Linda's career were similar to those reported by other senior women academics in South Africa: it rendered her unaware of her obligation to publish or the relevance of publications to her academic credibility (Maürtin-Cairncross, 2003).

What further emerged from the interviews with regard to mentoring is that, while a number of the women explicitly mention the direct and positive role mentors played in their publication careers, the men seem to be more hesitant in this regard. Only one male respondent, Leon, provided a relatively positive account of his mentors:

"My love of research comes from two sources. One is: I had good mentors, had good examples...I worked closely 
with people who gave you the message, loud and clear: 'Publish; research is part of your work...And my mentor also publishes a lot...I have already seen his list of publications, and it is a fairly impressive list. So, you get that sort of message very clearly".

Among the men, friendship, rather than mentorship, is emphasised, indicating a tendency towards equal-power relationships. "I don't know if I could ever call somebody a mentor", Sean remarks, "I had a very close collaboration with $K$ in the UK. And we're just friends now". Similarly, Martin's response, "I suppose I had the privilege to have some nice mentors to help me", indicates almost an indifference towards the role mentors played in his career. In his narrative, Ted refers to mentors in passing- "I was fortunate that I was taught by L, who was a genius, but who could explain anything to anyone"- and rather focuses on the indirect influence of role models from overseas:

\begin{abstract}
"Facilitators were other people overseas...I've had lots of heroes overseas. And I had lots of people I respect, and I still do. I look for heroes, great scientists. And I read their work; try to understand how they got around a problem that I might be facing".
\end{abstract}

Rather than emphasising their own mentor's contribution, the men tend to describe their own role as mentors. Jacob recalls "creating opportunities" for a student and younger colleague through his involvement in an international research group:

“...so that he could, for instance, become a research fellow, and in this waybecome involved in research projects".
For Jacob, it is of great importance to create such possibilities through the "knowledge...one has acquired over many years" and one's contacts abroad, in order to "reach out, become involved...enrich other people", rather than to "sit tight in [one's] ivory tower". Both Jacques and Ted view mentoring as integral to their "work" or "function". According to Jacques, this may imply helping a student to "hammer out" a publication, while Ted, views it as his "primary job" to:

“...facilitate and teach these young kids to be good scientists, and to provide them with the necessary skills, and resources that they need to be good scientists... It's not to accumulate everything for myself".

It is important to note that none of the women respondedtoprobesonmentoring in the way these men did. Rather, they describe their own dependence on mentors for guidance to a much greater extent than the men do.

\section{“You're busy developing lectures": early teaching load}

In contrast to men such as Charles, Leon and Bob, who experienced a productive graduate training period, most of the women identify full-time academic teaching as a constraint on the number of publications they could produce during their graduate training. This is especially true if training involved travelling abroad, which makes it "hard to settle down and publish", according to Thandi. She explains that when she arrived at an overseas university at the beginning of the 1980s, her children were "very, very young" (three and six years of age), and she only left when the eldest was becoming a teenager: 
"I had to look after them and do research for my PhD, and I had to...teach. I believed then...if I could survive that: nothing, nothing is difficult".

Similarly, Cecilia refers to the fact that full-time employment "certainly limits one's potential to publish, because you're busy developing lectures, and working flat-out", while Elmarie explains working "long on the D", because she was "busy the whole time" training her own students. Such experiences are mostly absent among the men respondents in this study. Only one, Sean, reported that his initially low publication output resulted from conducting his $\mathrm{PhD}$ research as a junior academic with a high teaching load.

An intriguing finding is that the female respondent who boasts the highest prePhD article count of all the respondentsmale or female-also interrupted her doctoral studies and in effect deviated from the linear (masculine) norm for academic careers. However, the effect of this discontinuity on Sarah's publication productivity was negligible. In fact, two to three years after she got married, Sarah entered what she describes as "an extremely productive time" in terms of publications, which she does not attribute to her $\mathrm{PhD}$, but rather to her marriage to a researcher, with whom she was running a research station at a time when both were employed full-time as researchers:

"I had absolutely no academic commitments. And that was really the best time for research, and I think I attribute my high productivity then to being able to do research full-time, and working with someone who was also doing research full-time".

Although a detailed discussion of the issue of spousal collaboration is beyond the scope of this paper, it is important to note that more than half of Sarah's publications are co-authored with her husband, and that the other female respondent who collaborates extensively with her husband (Beatrice) also mentioned the positive effect of this "conjugal" research collaboration on her publication productivity.

\section{The complex interplay among marriage, children and early academic careers}

Although marriage and children may indirectly impede publication productivity by foreshortening the academic career, as indicated by the CV data on the respondents' career ages and publication productivity, the qualitative data show that marriage may also provide the impetus for pursuing such a career, or for developing a more productive research focus. Also, the data suggest that a later career start does not necessarily exhibit cumulative disadvantage effects. Men and women academics may publish prolifically before attaining a PhD. If women have children, cumulative disadvantage effects may be countered by "making up" for low productivity at a later stage-when children "grow up" and become "less dependent" on their mother, according to Adéle:

\section{"My domestic circumstances are becoming easier, because now it is only my husband and me. So, my obligations are becoming less and less. So, I find that I actually have more time to my disposal than I had before, which allows me to keep up the pace".}

Linda agrees: "Even though your career is slower to take off, you build a kind of foundation which later, when your children are more free, you can build upon much more strongly", she explains. Eventually, she argues, one may actually 
"catch up" with one's male colleagues. In general, Linda experienced an increase in "space" as her children grew up, and when they started school, she could start attending conferences, and further her academic career in this way.

These findings seem to indicate that career difficulties related to motherhood are most salient at the stage when children are young. However, some women respondents counter this assumption. According to Delia, whose children are eleven and three years of age, it depends on the child:

"My oldest is much more complicated, much more time-demanding. It was very difficult when he was a baby, and I find it quite difficult now again, with all the carrying and fetching and whatever, to get him to various sports and whatever".

Beatrice-whose children are teenagersis of the opinion that, "it's getting progressively worse as the children get older".

\section{Men's career discontinuity}

The discontinuity so common at the initial stages of many of the women's academic careers is mostly absent among the male narratives - an observation that seems to supports the notion that women tend less than men towards orderly, linear career progression. However, career discontinuity is not a trait exclusive to female careers. Bob, for example, exhibits a five-year hiatus in his publication record, which he ascribes to a "typical midlife crisis":

Just a few years after reaching his life goal, or what he "always wanted to do as a little kid", i.e., becoming a professor at the age of forty in his chosen discipline, he started "really running out of" research ideas, which led him to start afresh by studying and the conducting research in a different discipline:

"I just chucked up my old ad hominem professoriate at lthe university where I had been working]... and of course everybody thought I'm totally crazy - and I became a student... at [another university]. I started over - completely over again".

Similarly, Leon acknowledges that he may be experiencing "writer's block", which has caused his publication outputs to "have plunged a lot the past two, three years", while Charles predicts such a slump in his publication productivity in the near future,

"because I am running out of a lot of
steam. I've been doing a lot of work
on [a particular topic], and I honestly
think I've written everything that I could
possibly write on that (just about). And I
feel that I'm writing the same thing for
the umpteenth time now".

Charles changes his main research focus every few years-in his own words, he "re-invents" himself-in an attempt to counter this boredom he experiences: "Its time to get out and do something different, otherwise you just get bored", he explains. Because such changes require intellectual retooling, they inevitable result in a temporary downturn in publication productivity.

Thus, fractured career paths are not necessarily limited to women academics only, but the genders do differ in terms of the origins of their career discontinuity. For the men, career "breaks" that decrease their publication productivity seem to be motivated by issues that are more internal or psychological in nature-running out 
of steam, or out of ideas, or experiencing a midlife crisis or "writer's block — while the women identify factors external to themselves, particularly marriage and children, as causing publication discontinuities.

\section{Conclusion}

The objective of the study reported in this paper was to develop a more indepth understanding of how genderrelated factors operating at the earlier career stages may influence the career publication productivity among some of South Africa's most productive academic researchers. The findings indicate that, in a matched sample of these academics, women tend to have less professional experience and initiate their publication careers at a later age than their male counterparts do, because they achieve doctoral status-a crucial determinant of publication productivity - at a later stage in their lives. These findings mirror those of previous studies (Asmar, 1999; Probert et al., 1998, cited in Chesterman, 2002; Xie and Shauman, 1998; Toren, 1991) that report women generally taking longer than their male counterparts to attain a $\mathrm{PhD}$.

The data further show that this genderrelated lag in completing a $\mathrm{PhD}$ is not the result of any lack of ability on the women's part: The women differ from the men in that they wrote their dissertations while their children were still quite young. They also tend to report time-consuming fulltime lecturing responsibilities during this stage in their careers to a much greater extent than the men do. As such, the women interviewed do not differ from South African women academics in general, whose experience of a lack of time for research due to their teaching commitments has been repeatedly documented (Maürtin-Cairncross, 2003; Van Staden et al., 2001; Thomson, 1994; Bethlehem, 1991, cited in Budlender, 1994). The women also tend to postpone, fracture or change focus in their early research careers, in order to accommodate theirhusband'scareerneeds.Thisresearch therefore reiterates the findings of other life-course studies, conducted both in South Africa (De la Rey, 1999) and abroad (Probert et al., 1998, cited in Chesterman, 2002), which indicate that the majority of women have discontinuous careers as a result of shaping their professional lives in relation to the lives of their partners and/or children.

It is therefore not surprising that the women in this study are shown to have published less pre-PhD peer-reviewed papers than the men. Combining the roles of wife, mother, doctoral student and full-time lecturer at the initial stages of an academic career was experienced by the women as extremely demanding, and it did not allow for much, if any, publication-a situation exacerbated by the underdeveloped research culture that characterised South African higher education institutions at the time.

Previous researchers have noted that childbearing and childcare may limit women's opportunities to further an academic research career overseas (Gale, 1980), or at least limit their work-related travel (Carretal., 1998). Toren (1991) found that young children and work overload associated with rearing of children limit, above all else, women scientists' mobility and opportunities to go abroad for a post-doctoral, sabbatical, or professional meetings and conventions. At the same time, the attendance of conferences, especially those outside one's own country, has been shown to be one of the most significant correlates of article publication productivity (Teodorescu, 2000). 
The present study provides further evidence of this gender-differential effect of family-responsibilities on women's early career mobility, and shows how its negative effects are amplified-forwomen in particular-by the lack of a dynamic research culture that characterised South African academia two to three decades ago. While the men tend to report a publication-enhancing environment that socialized them to value research in their careers, the women's more limited geographic mobility-primarily a result of their tendency to shape their careers around their family members' needsdecreased their chances early in their careers of being exposed to more dynamic research cultures overseas. These findings support Cole's (1979) suggestion that informal, socializing aspects of graduate training may be enormously consequential for future publication productivity, and should therefore be considered when attempting to explain the differential publication productivity found among men and women.

Some previous research has also indicated that women report feeling less mentored than men do (Landino and Owen, 1988), particularly when it comes to integration into professional networks (O'Leary and Mitchell, 1990). Somewhat contrary to these findings, the women in this study explicitly mention the positive, guiding role mentors and colleagues played in their early publication careers. The men, on the other hand, focus more on their equal-power relationships with their mentors and on their own role as mentors. This may indicate that women's research needs centre more strongly around mentorship and collegial support than is the case among men, or that they are more dependent upon collaboration with colleagues than men are, as Kyvik and Teigen (1996) found to be the case among Norwegian scientists. The finding could be linked to the fact that a highly selective group of women was studied, as Sonnert and Holton (1995) report that successful women scientists acknowledge support from colleagues and others to a greater extent than male scientists, who appear to be more independent and selfmotivated.

During apartheid South Africa, when the imposition of scientific boycotts and sanctions most probably had a "closing-off" effect on the publication productivity of academics in the country (Jacobs and Ingwersen 2000), dependency on collaboration was most probably heightened by women's lack of international exposure. Collegial support may also be especially important for women who experience additional family responsibilities and heavy administrative loads, as it mediates role overload (Fox, 1983; Reskin, 1978b), and it may also be more important for women who experience research and publication as solitary activities conducted in a hostile environment (Maürtin-Cairncross 2003).

The CV data on the South African respondents' career ages and publication productivity produce results similar to those already reported by Toren (1991), i.e. that a number of academic women tend to delay the earning of a $\mathrm{PhD}$ until having one or two children ${ }^{9}$. For the exceptionally productive women interviewed here, motherhood ultimately causes them to be what other South African researchers have termed "slow" or "late" starters, and therefore late achievers, in academia (Maürtin-Cairncross, 2003; Petersen and Gravett, 2000; De la Rey, 1999; White, 1989). As the accumulative advantage hypothesis (Cole and Cole, 1973) predicts, delaying the start of a publication career may cost these women dearly in terms of later publication productivity. 
The qualitative data, however, show how these cumulative disadvantage effects can be countered to a certain extent by women accelerating their publication productivity rate at a later stage in their lives, particularly when their children reach school-going age. However, the qualitative findings do not wholly support what previous researchers have thus far reported, i.e., that young children necessarily have a greater effect on a woman's career than older children do (Moultrie and De la Rey, 2003; Centre for Science Development, 1999; Kyvik and Teigen, 1996; Toren, 1991; Kyvik, 1990). Also, the common assumption that marriage always plays an impeding role in women's careers is countered by some of the case studies presented here, as a husband may initiate or strengthen his wife's research activity and publication productivity, particularly if spouses collaborate in their research endeavours.

Although the discontinuity so common at the initial stages of many of the women's academic careers is mostly absent among the male narratives, it is interesting to note that the men's careers do not necessarily exhibit the linearity suggested by other researchers, such as De la Rey (1999), Lie (1990) and Karp (1985). This demonstrates the importance of including men in any study that focuses on gender issues in the academic workplace, as empirical research seems to counter some of the assumptions that underlie research on women only. In terms of the reasons for career discontinuity, the genders do differ: The men who experience fractured publication careers do so not as a result of their family-related or teaching roles, but mostly because of fluctuations in internal motivation or drive experienced at a later stage in their careers.

The study further shows that the incompatibility between being a mother and a productive academic researcher is an empirically untenable stereotype even among South African women academics whose early careers were forged when patriarchal and apartheid ideologies predominated. Seven of the eight women interviewed had been married at least once, and have children. As they are among the most productive women in the country in terms of academic publications, their career publication productivity would be higher than that of any unmarried, childless academic women. This indirectly supports the counterintuitive findings of the large body of evidence, referred to in the introduction, which suggests that married women actually publish more than single women and/or that mothers publish more than childless women.

However, the qualitative findings of the present study preclude one from interpreting such results as evidence of a non-negative or even positive effect of marriage and/or children on publication productivity. It is therefore proposed that the productivity puzzle would be best solved by determining what has allowed highly productive women such as these to overcome the effects of family-related factors on their career publication productivity.

Finally, the findings also have bibliometric implications. Counting publications over a lifetime may be confounded by career age and therefore the time and opportunity to publish (Jackson, 2002; European Commission, 2000). Because women often postpone their PhD to raise small children, and thereforetohaveshorterpublicationcareer spans, and/or interrupt their research and publication momentum because of family-related demands on their time and energy, gender-comparisons in terms of such measures of publication productivity 
may systematically disadvantage women. It would therefore be more reasonable and equitable to determine the size of a gender gap in publication productivity by comparing the sexes in terms of the average output produced only during the years that they have actually published.

\section{Acknowledgements}

The author would like to thank her supervisor, Andrienetta Kritzinger, as well as anonymous reviewers for useful suggestions and comments on earlier drafts of this paper.

\section{Notes}

1 Qualitative research among women academics in South Africa has shown that it is still extremely rare for parenting to be co-equal (Walker, 1998), as parental identity is defined differentially for women and men: "Even when men were described as participating partners...this participation was much more limited compared to the woman's role" (De la Rey, 1999: 209).

2 The Centre was renamed in 2003 as the Centre for Research on Science and Technology.

3 In one exception, a respondent on the same campus as the author insisted on a face-to-face interview.

4 This extreme version of a contribution-based definition of what constitutes a scientist (Xie, 1989, cited in Xie and Shauman, 1998) is not uncommon: studies that, for a variety of reasons, have concentrated on an elite group of scientists who are major producers of scientific publications, include those of Astin and Davis [Astin and Davis, 1985; Astin, 1991; Davis and Astin, 1990], Cole and Singer (1991), and Sonnert and Holton (1995).
5 During apartheid, funding and support for research in the higher education system was based on racial grounds. Since the late 1990s it has therefore become common practice (although not formal policy) to distinguish between Historically "White" or Advantaged Universities (HAIs), and Historically "Black” or Disadvantaged Universities (HDUs) [see Bunting (2002) for more background information in this regard].

6 The National Research Foundation evaluation and rating system is a benchmarking system based on expert opinions from peers, locally and abroad. These expert reviewers base their opinions on the quality and impact of the research outputs and achievements of individual researchers in South Africa's higher education system. They assess each applicant's standing as a researcher based on his/her work over the past seven years (National Research Foundation 2007: 16). For more detailed information, visit http://www.nrf.ac.za/evaluation/.

7 In 2002, this South African government department was divided into separate departments: the Department of Science and Technology and the Department of Arts and Culture.

8 The fact that two of the respondents selected are married is coincidental.

9 The tendency to postpone the $\mathrm{PhD}$ in favour of starting a family may be related to the birth-rate of the country within which an academic woman is located, which as one reviewer pointed out, could explain similarities in this regard between Israel, where Toren's research was conducted, and South Africa: both countries are characterised by relatively high-birth rates compared to, for example, most European countries. 


\section{References}

Allison, Paul D. and John.A. Stewart (1974) 'Productivity Differences among Scientists: Evidence for Cumulative Advantage', American Sociological Review 39(4): 596-606.

Asmar, Christine (1999) 'Is there a Gendered Agenda in Academia? The Research Experience of Female and Male PhD Graduates in Australian Universities', Higher Education 38(3): 255-73.

Astin, Helen S. (1978) 'Factors Affecting Women's Scholarly Productivity', in Helen S. Astin and Werner Z. Hirsch (eds), The Higher Education of Women: Essays in Honor of Rosemary Park (New York: Praeger): 133-57.

Astin, Helen S. (1991) 'Citation Classics: Women and Men's Perceptions of their Contributions to Science', in Harriet Zuckerman, Jonathan R. Cole, \& John T. Bruer (eds), The Outer Circle: Women in the Scientific Community (New York: Norton): 57-70.

Astin, Helen S. and Alan E. Bayer (1975) 'Sex Discrimination in Academe', in Martha T.S. Mednick, Sandra Schwartz Tangri and L. Wladis Hoffman (eds), Women and Achievement: Social and Motivational Analyses (Washington, D.C.: Hemisphere): 372-95.

Astin, Helen S. and Diane E. Davis (1985)

'Research Productivity across the Life and Career Cycles: Facilitators and Barriers for Women', in Mary Frank Fox (ed), Scholarly Writing and Publishing: Issues, Problems, and Solutions (Boulder and London: Westview Press): 147-60.

Babbie, Earl and Johann Mouton (2001) The Practice of Social Research (Cape Town: Oxford University Press South Africa).

Barnett, Rosalind Chait, Carr, Phyllis L., Boisnier, Alicia D., Ash, Arlene S.,
Friedman, Robert H., Moskowitz, Mark A. and Laura Szalacha (1998) 'Relationships of Gender and Career Motivation to Medical Faculty Members' Production of Academic Publications', Academic Medicine 73(2): 180-86.

Budlender, Debbie (1994) 'Women in tertiary education', in Margaret Lessing (ed), South African Women Today (Cape Town: Maskew Miller Longman): 129-136.

Bunting, Ian (2002) ‘ The higher education landscape under apartheid', in Nico Cloete, Richard Fehnel, Peter Maassen, Teboho Moja, Helene Perold and Trish Gibbon (eds), Transformation in Higher Education: Global Pressures and Local Realities in South Africa (Landsdown: Juta and Co Pty Ltd): 58-86.

Carr, Phyllis L., Ash, Arlene S., Friedman, Robert H., Scaramucci, Amy, Barnett, Rosalind Chait, Szalacha, Laura, Palepu, Anita, and Mark A. Moskowitz (1998) 'Relation of Family Responsibilities and Gender to the Productivity and Career Satisfaction of Medical Faculty', Annals of Internal Medicine 129(7): 532-38.

Centre for Interdisciplinary Studies (2001) South African Science in Transition (University of Stellenbosch: Centre for Interdisciplinary Studies).

Centre for Science Development (1999) Women-in-Research Report on the Centre for Science Development Audit of Women Researchers and Academics in the Humanities and Social Sciences (Pretoria: Centre for Science Development, Human Sciences Research Council).

Chakravarthy, R., Chawla, A. and G. Metha (1988) 'Women Scientists at Work: An International Comparative Study of Six Countries', Scientometrics 14(1-2): 4374 .

Chesterman, Colleen (2002) 'Women's Executive Development in Australian 
Higher Education', in Gill Howie and Ashley Tauchert (eds), Gender, Teaching and Research in Higher Education: Challenges for the $21^{\text {st }}$ Century (Burlington: Ashgate): 236-47.

Cole, Jonathan R. (1979) Fair Science: Women in the Scientific Community (New York: Free Press).

Cole, Jonathan R. and Stephen Cole (1973) Social Stratification in Science (Chicago: The University of Chicago Press).

Cole, Jonathan R. and Harriet Zuckerman (1984) 'The Productivity Puzzle: Persistence and Change in Patterns of Publication of Men and Women Scientists', in Martin L. Maehr and Marjorie W. Steinkamp (eds), Advances in Motivation and Achievement, Vol. 2 (Greenwich, Connecticut: JAI Press): 217-58.

Cole, Jonathan R. and Harriet Zuckerman (1987) 'Marriage, Motherhood, and Research Performance in Science', Scientific American 256(2): 119-25.

Cole, Jonathan R. and Burton Singer (1991) 'A Theory of Limited Differences', in Harriet Zuckerman, Jonathan R. Cole \& John T. Bruer (eds), The Outer Circle: Women in the Scientific Community (New York: Norton): 277-310.

Committee on the Education and Employment of Women in Science and Engineering (1979) Climbing the Academic Ladder: Doctoral Women Scientists in Academe (Washington, D.C.: National Research Council, National Academy of Sciences).

Davis, Diane E. and Helen S. Astin (1990) 'Life Cycle, Career Patterns and Gender Stratification in Academe: Breaking Myths and Exposing Truths', in Suzanne Stiver Lie and Virginia E. O'Leary (eds), Storming the Tower: Women in the Academic World (London: Kogan Page): 89-107.
De la Rey, Cheryl M. (1998) A Review of the Experiences of Women in Higher Education in South Africa (University of Cape Town: Forum for African Women Educationalists South Africa).

De la Rey, Cheryl M. (1999) Career Narratives of Women Professors in South Africa. Thesis presented for the Degree of Doctor of Philosophy, University of Cape Town.

Department of Arts, Culture, Science and Technology (1998) National Research and Technology Audit: Human Resources in Science, Engineering and Technology (Pretoria: Foundation for Research Development and Department of Arts, Culture, Science and Technology).

Department of Education (2001) National Plan for Higher Education (Pretoria: Department of Education)

Etzkowitz, Henry, Kemelgor, Carol and Brian Uzzi (2000) Athena Unbound: The Advancement of Women in Science and Technology (Cambridge: Cambridge University Press).

European Commission, Research Directorate-General (2000) Science Policies in the European Union: Promoting Excellence through Mainstreaming Gender Equality. A Report from the European Technology Assessment Network (ETAN) Expert Working Group on Women and Science (Belgium: European Commission).

Fox, Mary Frank (1983) 'Publication Productivity among Scientists: A Critical Review', Social Studies of Science 13(2): 285-305.

Fox, Mary Frank (1995) 'Women and Scientific Careers', in S. Jasanoff, G.E. Markle, J.C. Petersen and T. Pinch (eds), Handbook of Science and Technology Studies (Thousand Oaks, CA.: Sage): 205-23.

Fox, Mary Frank and Caroline Faver (1985) 'Men, Women and Publication 
Productivity: Patterns among Social Work Academics', Sociological Quarterly 26(4): 537-49.

Gale, Fay (1980) 'Academic Staffing: The Search for Excellence', Vestes 23(1): 38.

Graham, Patricia Albjerg (1970) 'Women in Academe', Science 169 (3952): 128490.

Hamovitch, William and Richard D. Morgenstern (1977) 'Children and the Productivity of Academic Women', Journal of Higher Education 48(6): 63345.

Harper, Elizabeth P., Baldwin, Roger G., Gansneder, Bruce G. and Jay L. Chronister (2001) 'Full-Time Women Faculty off the Tenure Track: Profile and Practice', The Review of Higher Education 24(3): 237-57.

Helmreich, Robert L., Spence, Janet T., Beane, William E., Lucker, G William and Karen A. Matthews (1980) 'Making it in Academic Psychology: Demographic and Personality Correlates of Attainment', Journal of Personality and Social Psychology 39(5): 896-908.

Jackson, Sue (2002) 'Transcending Boundaries: Women, Research and Teaching in the Academy', in Gill Howie and Ashley Tauchert (eds), Gender, Teaching and Research in Higher Education: Challenges for the $21^{\text {st }}$ Century (Burlington: Ashgate): 20-32.

Jacobs, Daisy and Peter Ingwersen (2000) 'A Bibliometric Study of the Publication Patterns in the Sciences of South African Scholars 1981-96', Scientometrics 47(1): 75-93.

Karp, David A. (1985) 'Gender, Academic Careers, and the Social Psychology of Aging', Qualitative Sociology 8(1): 928.

Kyvik, Svein (1990) 'Motherhood and Scientific Productivity', Social Studies of Science 20(1): 149-60.
Kyvik, Svein (1991) Productivity in Academia: Scientific Publishing at Norwegian Universities (Oslo: Norwegian University Press).

Kyvik, Svein and Mari Teigen (1996) 'Child Care, Research Collaboration, and Gender Differences in Scientific Productivity', Science, Technology and Human Values 21(1): 54-71.

Landino, Rita A. \& Steven V. Owen (1988) 'Self-Efficacy in University Faculty', Journal of Vocational Behavior 33: 114.

Levinson, Wendy, Tolle, Susan W., and Charles Lewis (1989) 'Women in Academic Medicine: Combining Career and Family', New England Journal of Medicine 321(22): 1511-17.

Lie, Suzanne Stiver (1990) 'The Juggling Act: Work and Family in Norway', Pp. in Suzanne Stiver Lie and Virginia E. O'Leary (eds), Storming the Tower: Women in the Academic World (London: Kogan Page): 108-28.

Long, J. Scott (1990) 'The Origins of Sex Differences in Science', Social Forces 68(4): 1297-315.

Long, J. Scott (1992) 'Measures of Sex Differences in Scientific Productivity', Social Forces 70(5): 159-78.

Long, J. Scott and Robert McGinnis (1981) 'Organisational Context and Scientific Productivity', American Sociological Review 46(Aug.): 422-42.

Luukkonen-Gronow, Terttu and Veronica Stolte-Heiskanen (1983) 'Myths and Realities of Role Incompatibility of Women Scientists', Acta Sociologica 26(3/4): 267-80.

Maürtin-Cairncross, Anita (2003) Creating 'Space' for Publication: Challenges Faced by Women Academic Staff at Historically Black South African Universities. Thesis Presented for the Degree of Doctor of Philosophy, University of the Western Cape. 
Moultrie, Alison and Cheryl M. De la Rey (2003) 'South African Women Leaders in Higher Education: Professional Development Needs in a Changing Context', McGill Journal of Education 38(3): 407-20.

Nakhaie, M. Reza (2002) 'Gender Differences in Publication among University Professors in Canada', Canadian Review of Sociology and Anthropology 39(2): 151-79.

National Research Foundation (2001) Women-in-Research Audit Report (Pretoria: National Research Foundation Evaluation Centre).

National Research Foundation (2007) Evaluation and Rating: Facts and Figures 2007 (Pretoria: National Research Foundation).

O'Leary, Veronica E. and Judith M. Mitchell (1990) 'Women Connecting withWomen: Networks and Mentors', in Suzanne Stiver Lie and Virginia O'Leary (eds), Storming the Tower: Women in the Academic World (London: Kogan Page): 58-74.

Petersen, N. and S. Gravett (2000) 'The Experiences of Women Academics at a South African University', South African Journal of Higher Education 14(3): 169-76.

Pouris, Anastassios (2003) 'South Africa's Research Publication Record: The Last Ten Years', South African Journal of Science 99(9/10): 425-8.

Prozesky, Heidi Eileen (2006a) 'Gender Differences in the Journal Publication Productivity of South African Academic Authors', South African Review of Sociology 37(2): 87-112.

Prozesky, Heidi Eileen (2006b) Gender Differences in the Publication Productivity of South African Academic Scientists. Dissertation Presented for the Degree of Doctor of Philosophy, Stellenbosch University.
Reskin, Barbara F. (1977) 'Scientific Productivity and the Reward Structure of Science', American Sociological Review 47(3): 491-504.

Reskin, Barbara F. (1978a) 'Scientific Productivity: Sex, Location and the Institution of Science', American Journal of Sociology 83(5): 1235-43.

Reskin, Barbara F. (1978b) 'Sex Differentiation and the Social Organisation of Science', in J. Gaston (ed), The Sociology of Science (San Francisco: Jossey-Bass Publishers): 637.

Sax, Linda J., Hagedorn, Linda Serra, Arredondo, Marisol and Frank A. Dicrisi III (2002) 'Faculty Research Productivity: Exploring the Role of Gender and Family-Related Factors', Research in Higher Education 43(4): 423-46.

Shefer, Tammy, Van Niekerk, Ashley, Duncan, Norman and Cheryl M. de la Rey (1997) ‘Challenging Authorship and Authority in Psychology: A Publishing Initiative', Psychology in Society 22: 3746.

Simon, Rita J., Clark, Shirley M. and Kathleen Galway (1967) 'The Woman PhD: A Recent Profile', Social Problems 15(2): 221-36.

Sonnert, Gerhard (1999) 'Women in Science and Engineering: Advances, Challenges and Solutions', in Cecily Cannan Selby (ed), Women in Science and Engineering: Choices for Success. Annals of the New York Academy of Sciences, Vol. 869 (New York: The New York Academy of Sciences): 34-57.

Sonnert, Gerhard and Gerald Holton (1995) Who Succeeds in Science? The Gender Dimension (New Brunswick, NJ: Rutgers University Press).

Stephan, Paula E. and Sharon G. Levin (1992) Striking the Mother Lode in Science: The Importance of Age, Place, and Time (New York: Oxford University Press). 
Teodorescu, Daniel (2000) 'Correlates of Faculty Publication Productivity: A Cross-National Analysis', Higher Education 39(2): 201-22.

Thomson, Jennifer A. (1994) 'Women in Science', in Margaret Lessing (ed), South African Women Today (Cape Town: Maskew Miller Longman): 26774.

Toren, Nina (1991) 'The Nexus between Family and Work Roles of Academic Women in Israel: Reality and Representation', Gender Roles 24(1112): 651-67.

Van Staden, Fred, Boon, Christine and Ingrid Dennill (2001) 'Research and Publications Output: A Survey of the Psychology Department at UNISA', South African Journal of Psychology 31(3): 50-56.

Walker, Melanie (1998) 'Academic Identities: Women on a South African Landscape', British Journal of Sociology of Education 19(3): 335-54.

Wanner, Richard A., Lewis, Lionel S. \& David I. Gregorio (1981) 'Research Productivity in Academia: A Comparative Study of the Sciences, Social Sciences and Humanities', Sociology of Education 54(4): 238-53.
White, Caroline (1989) 'Report of a Study of Employment Opportunities for Women at the University of Cape Town', in Glen Goosen, Martin Hall and Caroline White (eds), Rethinking UCT: The Debate over Africanisation and the Position of Women - Occasional Paper No. 6/1989 (Centre for African Studies, University of Cape Town): 86-116.

Williams, Gareth, Blackstone, Tessa and David Metcalf (1974) The Academic Labour Market: Economic and Social Aspects of a Profession (Amsterdam: Elsevier Scientific Publishing Company).

Xie, Yu and Kimberlee Shauman (1998) 'Gender Differences in Research Productivity: New Evidence about an Old Puzzle', American Sociological Review 63(6): 847-70.

Heidi Prozesky

Department of Sociology and Social Anthropology

Stellenbosch University

South Africa

Email:hep@sun.ac.za 